\title{
The Exploration of the Curriculum Reform in Kindergarten Mathematics Education
}

\author{
Guo-cheng $\mathrm{LI}^{1, \mathrm{a},{ }^{*}}$ \\ ${ }^{1}$ Linyi University, Feixian, Shandong, China \\ ayulgc@126.com
}

\begin{abstract}
Keywords: Kindergarten Mathematics Education, Curriculum Standard, Curriculum Reform.
\end{abstract}

\begin{abstract}
The mathematics education for children is not only required by the environment adaptation for children, but also by the mathematical logic ability development for children. There are neither kindergarten curriculum standards, nor detailed standard in specific field for kindergarten in China. The enlightenment in the exploration of the curriculum reform in kindergarten mathematics education: strengthen the importance of kindergarten mathematics education in kindergarten education system; Reinforce the mathematics curriculum cohesion from kindergarten to elementary education; Optimize the kindergarten mathematics education system; Enhance the curriculum content in kindergarten mathematics education.
\end{abstract}

\section{Introduction}

Mathematics played an important role in human civilization, which promoted the great progress of science and technology, as well as brought infinite benefits for human production and life. Mathematics not only delivered us the knowledge which closely related to daily life, but also trained us with the thinking and logical reasoning abilities. It is because of the importance of Mathematics to society and the people in the education reform of 1st century, all countries all over the world have listed mathematics education into the important basic education course. The mathematics education for children is not only required by the environment adaptation for children, but also by the mathematical logic ability development for children. However, the preschool period is in the key and sensitive stage for mathematics education development, the enlightenment education in mathematics is much more significant.

\section{The Difficulties during the Process of Kindergarten Mathematics Education}

Huang Jin, the vice president in school of preschool education and special education in East China Normal University, said that mathematics education is one of the most difficult areas for teacher, in the course of current kindergarten education [1]. The mathematics educational experts presented several questions in the kindergarten mathematics education seminar in 2013. What are the specific content in "Numbers, calculation, figure, measurement and mode" of the kindergarten mathematics education? How is the relationship between them? Which are the important aspects that teachers should pay more attention to? What is the mechanism to achieve these cognitive abilities? It is indicated during the interviews with kindergarten teachers that the teachers' guide book is the main reference for kindergarten mathematics education. While teachers are quite confused by the series of questions like construction theories of preschool mathematics course, the teaching goals, the teaching content, the teaching 
standard and principles to select the proper teaching content, as well as how to obtained the better teaching efficiency. What is the edition standard and basis for preschool teachers guide book? All of these problems should be solved by a basic guidance material, which will help to better guide the implementation of the kindergarten mathematics education.

\section{Strengthen the Position of Mathematics Education in the Kindergarten Education}

I think we need to strengthen the position of mathematics education in the kindergarten education. Firstly, it is discovered in the documentation in related with Chinese kindergarten mathematics education that The Kindergarten Calculation Teaching Outline has formed in 1950s in The Kindergarten Tentative Teaching Outline (Draft), which consisted of clear teaching goals, teaching outline, teaching and equipment key points. In 1980s, The Kindergarten Education Guides (Trial Draft) has introduced the mathematics teaching content and requirement in junior kindergarten, the middle class of kindergarten and senior kindergarten. It showed that from 1950s-1980s, the "Mathematics" has been announced as an independent discipline in the documentation for Chinese kindergarten mathematics education. Secondly, in terms of scientific concept, the understanding of "Science" in China is mainly refers to the knowledge of nature, society and thinking system [2]. However, the narrow sense of science education refers to the natural science. It is not reasonable to put the science in the new outline into broad or narrow perspective. If refers to general science, the area of "Society" should also been put into science, while if in narrow sense, mathematics should have its comparatively independence. Thirdly, from the perspective of mathematics development, mathematics has firmed the equal status with science after experiencing the period of "mathematics is the nature of science", "mathematics is the tool of science" and "mathematics and science are independent from each other" [3]. Fourthly, from the discipline of mathematics, it has its own independent value and rules. Fifthly, the practice of foreign kindergarten education has provided the evidence. The kindergartens in U.S. Always consider mathematics education as an independent system. Kindergarten mathematics education and science education are two related but separate content. Although, British emphasis that mathematics should be in associated with life and other course, they still emphasis that mathematics and science have their relatively independent status. Therefore, we should not only be aware of the close connection in mathematics and science, but also reinforce the position of mathematics in kindergarten education.

\section{Reinforce the Mathematics Curriculum Cohesion from Kindergarten to Elementary Education}

Our current educational system has added kindergarten education into formal schooling system. But the character and length of school in kindergarten education is different from elementary education. The length of kindergarten is 3 years, while 5 or 6 years in elementary school. So the mathematics curriculum cohesion from kindergarten to elementary education should be reinforced in teachers and curriculum.

For mathematics curriculum, depend on Chen Bozhang's study on primary school curriculum structure, the main issue in curriculum cohesion is knowledge overlap or discontinuous [4]. This phenomenon needs the teachers' communication between kindergarten and elementary school. Moreover, it also needs the support from all kinds 
of resources, such as the instruction from curriculum and education experts, social groups and managers.

In China, the kindergarten and elementary education are separated from each other and there's not clear guidance about the cohesion. Curriculum standard has played an important role in curriculum implementation, teaching design and teaching evaluation. During the basic curriculum reform, China has promulgated The Mathematics Curriculum standard in Full-time Compulsory Education (Experiment Draft) and new Outline, which cut the documentation about kindergarten and elementary education cohesion. Therefore, it requires the curriculum and education experts combine the kindergarten curriculum with elementary curriculum, and then establish a kindergarten and elementary education cohesion guidance. It needs the support from all kinds of institutions and resources and reinforce the mathematics curriculum cohesion from kindergarten to elementary education, which will provide the curriculum cohesion pattern from different level.

\section{Enhance Kindergarten Mathematics Education Curriculum System}

The experts in U.S. put forward the basic thought in mathematics education firstly, which included equality, curriculum, education, study, evaluation and technology, etc [5]. Chinese new Outline has indicated in these six aspects. For the principle of equality, it is indicated that kindergarten education is for the healthy growth of the children. And educators should respect individual's differences with individualized education, and strive to help every child for their satisfaction and success. Education system should be designed for all children instead of for the gifted children. It should pay more attention to individual development. However, all of these ideas did not form a complete guidance system.

For the goal of kindergarten mathematics curriculum, The Kindergarten Mathematics Teaching Outline in 1950s has declared the general goal, teaching outline, teaching key point and main equipment in mathematics. The Kindergarten Education Outline (Trail Draft) in 1980s has come up with the general goal and content in regard of student's age and level. The educational goal in 1950s-1980s is focus on knowledge and skills, they always use "Recognition" "Teaching" and "Learning" to describe the educational goal. After the publish of The Kindergarten Procedures (Trail) in 1989, the educators in China started to focus on the cultivation of emotion, attitude and interests. It also has been emphasized in the mew Outline in 2000s with much more attention to emotion and attitude. They often use "Feeling" and "Experience" to describe educational goal. However, the requirement for educational goal by basic education reform is to pay more attention to the combination of knowledge and skill, procedure and method, emotion and attitude. Thus, the presentation of kindergarten mathematics curriculum goal should be improved.

For the content standard of kindergarten mathematics education, the research on 1950s-1980s has presented the content and specific goals of mathematics education. The content in 1980s is various and much more detailed than 1950s. In comparison of mathematics content in 1950s and 1980s, the latter one is richer in content and completer in knowledge system. Till to 2000 s, the content and requirement in new Outline is comparatively in general, such as "To motivate the children's interests in numbers, amounts, shapes, time and space of the surrounding environment, and to build up the primary number concept, then encourage the children to solve the simple issues in life and games by simple mathematical method", "the numbers, amounts, time and 
space". There's no specific explanation on the content and goals. The expression in this document is relatively concise and general, although it is flexible; it is not conductive to master the detailed objective and content for teachers, which will easily cause the randomness for teaching.

In general, the published documentations for kindergarten mathematics education should be improved in the aspects of mathematics teaching principles, curriculum goals, curriculum content, content goals, teaching procedure goals and case analysis.

\section{Enhance the Curriculum Content of the Mathematics Education}

In concluding with the curriculum documentations in 1950s-1980s and 2000s, the basic curriculum content of mathematics education is included with 5 aspects in numbers, amounts, shape, time and space. While the U.S. education content has added "Algebra" and "Probability and mathematical statistics" in the basis of those 5 aspects. The most important point in algebra is modeling phenomenon. The patterns of early activity can lay a foundation for abstract mathematics learning activities. Children can master the nature of the objects through cognition, generalization, comparison and analyze. Based on the profound influence of the pattern recognition of children's mathematical development, U.S. has built the specific rules in children model ability in course standard of kindergarten mathematics education. While, China did not recognize the pattern as an independent concept in kindergarten mathematics education. It is much more important to cultivate children's data collection and analyze information abilities through "Probability and statistics" [6]. Children can forecast the development trend of things, through comparatively vivid image representation, applying simple date to gain the information, and then deal with information. Based on the important role and educational appropriateness of "Algebra" and "Probability and mathematical statistics", China should implant these two aspects into kindergarten mathematics education.

Increasing the estimate content in the field of "number and operation" in the content system. As the importance component in mathematics, estimation played an important role in our daily life. So, teachers should provide some mathematical situation to let student apply the estimation into problem solving process which will help children in their consciousness of estimation. Estimation is added into elementary mathematics education for junior students, it is necessary to encourage senior kindergarten children familiar with estimation. "Geometry" is the knowledge in "shape and space", while we are only in refers to Euclidean geometry, we should also concern about the knowledge such as "coordinate geometry", "geometric modeling", "transformation composition" and so on.

\section{Summary}

Currently, it is increasingly in fierce competition, the core of the social competition is talent competition. Talent competition is the key to education and the education competition is focus on the courses. Course is the model to cultivate the talents, which has its long-term and systematic characteristics. To establish the curriculum standard in kindergarten mathematics education helps to enrich the curriculum theories in kindergarten. Meanwhile, it is a significant guideline to the practice of kindergarten teachers, which is also important for China's development. 


\section{Reference}

[1] Huang Jin, The Study on the Relations in the Implement of Chuansi Kindergarten Mathematics Education [J]. Early Childhood Education, 2010, (16).

[2] Ai Ailing, Comparison of the Difference in Kindergarten Education Between China and U.S. [J]. Comparative Education Review, 2001,(1).

[3] Pan Yuejuan, The Reflection on the Current Policies in Kindergarten Mathematics Education [J]. Studies in Preschool Education, 2005, (3).

[4] Chai Saifei, The Case Study on Mathematics Curriculum Cohesion from Kindergarten to Elementary Education [D]. Chongqing: School of Education, Southwest Normal University. 2005.

[5] Zhou Xin, U.S. Preschool Mathematics Education Standard and Strategy [J]. Early Childhood Education. 2003, (9).

[6] Zhou Xin, The Early Development of Children's Number Concept [M], Shanghai: East China Normal University Press, 2004. 